\title{
Software for pattern recognition of the larvae of Aedes aegypti and Aedes albopictus
}

\author{
Programa de computador para reconhecimento da \\ larva de Aedes aegypti e Aedes albopictus \\ André Iwersen de São Thiago', Emil Kupek², Joaquim Alves \\ Ferreira Neto $^{3}$ and Paulo de Tarso São Thiago ${ }^{2}$
}

\begin{abstract}
Software for pattern recognition of the larvae of mosquitoes Aedes aegypti and Aedes albopictus, biological vectors of dengue and yellow fever, has been developed. Rapid field identification of larva using a digital camera linked to a laptop computer equipped with this software may greatly help prevention campaigns. Key-words: Aedes aegypti. Larva. Pattern recognition.
\end{abstract}

Resumo Foi desenvolvido um programa de computador para reconhecimento da larva de Aedes aegypti $e$ Aedes albopictus, vetores biológicos de dengue e febre amarela. O programa possibilita rápida identificação da larva no campo, através de uma câmera digital ligada ao computador portátil, assim podendo ajudar açốes preventivas.

Palavras-chaves: Aedes aegypti. Larva. Reconhecimento de padrões.

Among mosquito-borne diseases considered a serious public health problem in tropical and subtropical areas all over the world, dengue is the most recent epidemic ${ }^{3}$. In Brazil, in addition to malaria and yellow fever in the Amazon region, dengue drew the attention of public health authorities in the decade of 1990 . The epidemic has become endemic in large cities of the North such as Belém, the capital of the federal state of Pará, and has spread south to large urban areas such as Belo Horizonte and Rio de Janeiro. The principal reason for this epidemic is the dissemination of the mosquito Aedes aegypti, which also transmits yellow fever. With the exception of Canada, Chile and Bermuda, it has infested all other countries in the Americas ${ }^{5}$. The spread of the mosquito is aided by the fact that it does not have natural competitors to limit its dissemination, as well as by a huge increase in volume and speed of modern road and air transportation, by disorganized urbanization with frequent use of open water storage tanks and drums among slum dwellers, and by recently acquired resistance of the mosquito to the chlorine insecticides ${ }^{5}$. As none of these risk factors is likely to be significantly reduced in the near future and there is no effective vaccine ${ }^{7}$, long-term vector control remains the principal weapon against dengue. A failure to establish efficient vector control can be extremely costly as the 1994 epidemic illustrates when dengue hemorrhagic fever reached almost $50 \%$ of fatality in the Brazilian federal state of Ceará6.

One of the difficulties in vector control is the lack of trained professionals able to identify the presence of the larva of the mosquito responsible for the disease transmission. This responsibility has recently been delegated to the municipalities, many of which are very poor, geographically isolated and ill equipped to deal with the scale of the problem. In this situation, a rapid computer-aided identification of the larvae may be of great help in controlling not just dengue, but also malaria and yellow fever vectors.

1. Departamento de Engenharia Elétrica do Centro Tecnológico da Universidade Federal de Santa Catarina, Florianópolis, SC. 2. Departamento de Saúde Pública do Centro de Ciências de Saúde da Universidade Federal de Santa Catarina, Florianópolis, SC. 3. Fundação Nacional de Saúde do Ministério da Saúde, Brasília, DF.

Address to: Prof. Emil Kupek. Dept ${ }^{\circ}$ de Saúde Pública/CCS/UFSC. Campus Universitário Trindade, 88040-900 Florianópolis, SC, Brasil.

Tel: 5548 249-9443; Fax: 5548 331-9542.

E-mail:kupek@ repensul.ufsc.br

Recebido para publicação em 10/10/2000. 
Aedes aegypti and Aedes albopictus are principal vectors of dengue in Latin America and Asia, respectively ${ }^{5}$. Therefore, it is important to distinguish between the two at the stage of the larva in order to direct eradication efforts. This work describes software developed to this end. It classifies a digitized image of the larva of Aedes mosquitoes into aegyptior albopictus species using a deterministic rule based on morphological characteristics of the larvae ${ }^{2}$.

There are three main phases in the process of larvae identification using this software. First, the larva of Aedes mosquito is identified in its natural habitat based on its specific movements which are distinguishable from other genera. Second, the larva is placed on a slide, its image is amplified via microscope at least 40 times and focused on the eighth segment of the larva, then a black-andwhite photograph is taken from a camera mounted on the microscope. The photograph is subsequently digitized (top part of Figure 1) and filtered until a triangular patch of scales - dark dots on top and mid part of Figure 1 - becomes clearly recognizable. Third, the curvature of this feature (lower part of Figure 1) is calculated and used as the classification criterion.
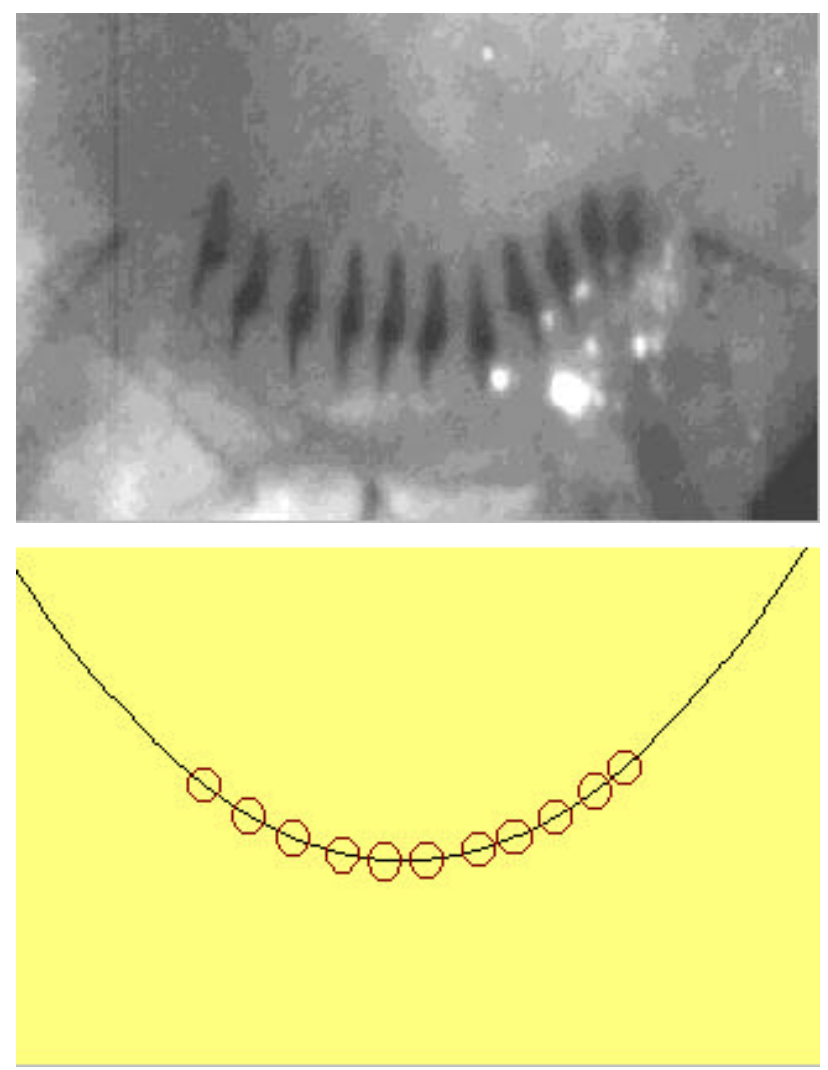

An experienced entomologist with more than twenty years of practice in detecting the difference between the larvae of Aedes aegypti and Aedes albopictus according to a well established nomenclature ${ }^{2}$ in the Brazilian National Health Foundation (Fundação Nacional de Saúde) determined the validity of the classification. His expert diagnosis was based on microscopic examination of the larvae using 100 times magnification. Using this as a gold standard, 24 larva images - 12 for each of the two Aedes species analyzed - were $100 \%$ successfully classified by the software. The classification rule implemented in the software was based on information elicited from the expert.

Further steps are planned in refining the software. First, a digital camera with sufficient resolution and linked to the computer can be used instead of a microscope, thereby giving an almost instant answer to the classification problem on the site where the larvae are collected. Second, larvae of other species and genera of mosquitoes can be included in the discrimination task, depending on the local variety and specific needs. Third, variations in the stage of the development of larva should be better explored as they determine not only the size

Figure 1 - Three main phases in the larva image processing. 
but also the detectability of specific morphological characteristics used for the classification. Finally, large samples of larvae should be tested and checked against the traditional method (identification by experts using light microscopy) to cross-validate the results and calculate sensitivity and specificity of the computer classification.

Rapid on-the-spot identification of the larvae with this software can be linked with other technological innovations such as satellite surveillance of climatic and ambiental conditions necessary for proliferation of mosquitoes ${ }^{1}$. High resolution of the satellite images can point to the areas of highest risk that need further terrestrial examination. Eradication campaigns may greatly benefit from better allocation of resources based on precisely located and rapidly diagnosed presence of the larvae.

\section{ACKNOWLEDGEMENTS}

The authors are very grateful to Silvia Modesto Nassar and Masanao Ohira from Departamento de Informática e Estatística, Universidade Federal de Santa Catarina, and Nilson Rodrigues Barreiros from Universidade Federal de Amazonas, for their help in obtaining the equipment necessary for photographing the larvae of Aedes aegypti and Aedes albopictus.

\section{REFERENCES}

1. Beck LR, Lobitz BM, Wood BL. Remote sensing and human health: New sensors and new opportunities. Emerging Infectious Diseases 6:217-227, 2000.

2. Forattini OP. Entomologia médica. Editora da Universidade de São Paulo, São Paulo, vol. 2, 1965.

3. Gubler DJ, Clark GG. Dengue/dengue hemorrhagic fever: The emergence of a global problem. Emerging Infectious Diseases 1:55-57, 1995

4. Pan American Health Organization. Dengue and dengue hemorrhagic fever in the Americas: Guidelines for prevention and control. Pan American Health Organization. Scientific Publication $\mathrm{n}^{\circ}$ 548, Washington, 1994.

5. Pinheiro PP, Chuit R. Emergence of Dengue Hemorrhagic Fever in the Americas. Infections in Medicine 15:244-251, 1998.

6. Vasconcelos PFC, Menezes DB, Melo LP. A large epidemic of dengue fever with dengue hemorrhagic cases in Ceara, Brazil, 1994. Revista do Instituto da Medicina Tropical de São Paulo 37:253-255, 1995.

7. World Health Organization. Dengue haemorrhagic fever: Diagnosis, treatment and control. World Health Organization, Geneva, 1997. 